\title{
Exploitation of reproductive barriers between Macrobrachium species for responsible aquaculture and biocontrol of schistosomiasis in West Africa
}

\author{
Amit Savaya-Alkalay ${ }^{1}$, Papa Demba $\mathrm{Ndao}^{2,3}$, Nicolas Jouanard $^{3}$, Ndeye Diane ${ }^{2,3}$, \\ Eliahu D. Aflalo ${ }^{1}$, Assaf Barki ${ }^{4}$, Amir Sagi ${ }^{1, *}$ \\ ${ }^{1}$ Department of Life Sciences and the National Institute for Biotechnology in the Negev, Ben-Gurion University, PO Box 653, \\ Beer Sheva 84105, Israel \\ ${ }^{2}$ Université Gaston Berger - BP 234 Saint-Louis, Senegal \\ ${ }^{3}$ Biomedical Research Center Espoir Pour La Santé, 263 route de la Corniche, Sor, Saint-Louis, Senegal \\ ${ }^{4}$ Department of Poultry and Aquaculture, Institute of Animal Science, Agricultural Research Organization, Volcani Center, \\ Bet Dagan, Israel
}

\begin{abstract}
Macrobrachium prawns are voracious predators of the freshwater snails that host the flatworms responsible for bilharzia (schistosomiasis), a health burden in many African countries. A novel strategy to decrease the disease in Africa involves the use of prawns as biocontrol agents of the snails. Although the endemic African river prawn Macrobrachium vollenhovenii is a natural candidate for aquaculture and biocontrol, efforts to domesticate it have been unsuccessful to date, and it is not available in the large quantities required for aquaculture and biocontrol. The Asian giant prawn Macrobrachium rosenbergii has been cultured worldwide for decades. Recently, novel biotechnologies were developed to create monosex (all-male) non-breeding populations for aquaculture that we suggest are also ideal for biocontrol in Africa. Since the above 2 prawn species are of the same genus, exhibit similar sizes and require a female pre-mating molt prior to egg fertilization, the potential for cross-breeding between the 2 species must be tested. To assure that all-male populations of $M$. rosenbergii will not pose such an ecological threat, we carried out cross-breeding experiments with $M$. vollenhovenii. Both interspecies encounters and attempts at artificial insemination revealed that fertilization does not occur between the 2 species. Our results demonstrate both behavioral and physiological pre-zygotic reproductive barriers between these species. We suggest that all-male $M$. rosenbergii can be used as an aquaculture species and as a biocontrol agent in areas where $M$. vollenhovenii occurs without concern for hybridization.
\end{abstract}

KEY WORDS: All-male populations - Artificial insemination - Bilharzia (schistosomiasis) · Biocontrol $\cdot$ Cross-breeding $\cdot$ Macrobrachium $\cdot$ Reproductive barrier $\cdot$ Aquaculture

\section{INTRODUCTION}

Freshwater prawns from the genus Macrobrachium are produced commercially in various countries around the world, with global production amounting to more than 500000 tons annually (www.fao.org/

${ }^{*}$ Corresponding author: sagia@bgu.ac.il fishery/). One of the most widely cultured species, $M$. rosenbergii, attracted considerable research attention when it was shown that its yields could be markedly increased through the use of novel monosex culture technologies developed for the aquaculture industry. All-male prawns are produced through a temporal

(C) The authors 2018. Open Access under Creative Commons by Attribution Licence. Use, distribution and reproduction are unrestricted. Authors and original publication must be credited. 
RNA interference manipulation that reverses the phenotypic sex of males to 'neo-females', i.e. genotypic males that function as females. Since male prawns are homogametic with respect to their sex chromosomes (ZZ), when a neo-female is crossed with a normal male, the progeny is $100 \%$ male (Ventura et al. 2012).

Recently, it was suggested that monosex $M$. rosenbergii populations can be exploited as biocontrol agents (Savaya-Alkalay et al. 2018). Support for this suggestion is found in previous studies indicating that the voracious predation abilities of Macrobrachium prawns could be applied in the biocontrol of a variety of snails that cause extensive economic damage and that pose significant threats to human health (Roberts \& Kuris 1990, Sokolow et al. 2014, 2016, Swartz et al. 2015, Savaya-Alkalay et al. 2018) For example, some species of freshwater snails are carriers of parasites that compromise human health and impose a massive burden on health services (e.g. schistosomiasis [bilharzia]), and others cause extensive damage in the aquaculture industry (e.g. Centrocestus spp. as fish parasites) and in the agriculture sector (e.g. apple snails as rice paddies pests) (Mitchell et al. 2007, Cowie \& Hayes 2012, Savaya-Alkalay \& Sagi 2016).

A most noted concern is schistosomiasis, a parasitic disease caused by a flatworm Schistosoma spp. that requires 2 hosts, a snail and a vertebrate (human, for example). It is most common in Africa, where more than 200 million people are infected and nearly 400 million are at risk (Sokolow et al. 2017). The Senegal River Basin has experienced the most drastic outbreak ever recorded of schistosomiasis in the past three decades (Sokolow et al. 2017). Following the completion of the Diama dam upstream of the Senegal River Estuary, the prevalence and intensity of schistosomiasis rapidly increased in the villages and towns in the region (Southgate 1997). One reason suggested for that outbreak is the fact that the dam prevents the local prawn species $M$. vollenhovenii from completing its life cycle, which requires access to the estuary. The dam prevents female prawns from migrating downstream toward the estuary where they would normally release their larvae. Similarly, their post-larvae offspring are confronted with the same problem, as their migration upstream toward the fresh water of the Senegal River is also blocked (Bauer 2011, Savaya Alkalay et al. 2014). The absence of prawns - a major predator of freshwater snails - upstream of the dam has thus created ideal growth conditions for freshwater snails, the secondary host of Schistosoma parasitic worms (Savaya Alkalay et al. 2014).
As a complementary measure to control schistosomiasis, there has been a preliminary attempt to reintroduce local prawns to water points in villages upstream of the Diama dam together with concomitant medical treatment provided to the children in the villages and monitoring of the prevalence and intensity of the Schistosoma burden in their body (Sokolow et al. 2015). Because this preliminary study yielded promising results, today a larger experiment is being conducted using prawns collected in the wild (www.theupstreamalliance.org).

However, to scale up such operations and obtain significant results regarding the effectiveness of Macrobrachium prawns as disease-reducing agents, there is a need for large quantities of inexpensive prawns, which is a challenge when using an undomesticated species such as $M$. vollenhovenii. Due to its large size and wide distribution throughout the west coasts of Africa (Senegal in the north to Angola in the south), numerous attempts to complete its life cycle for aquaculture use under hatchery conditions have been made in the past 25 yr. Unfortunately, none have succeeded in overcoming the obstacles to breeding $M$. vollenhovenii as an aquaculture product (Marioghae 1988, Willfuhr-Nast et al. 1993, Marioghae \& Ayilna 1995, Makombu et al. 2014).

Since $M$. rosenbergii prawns are readily available in the aquaculture industry, we recently suggested using non-breeding all-male $M$. rosenbergii populations for responsible aquaculture and as biocontrol agents wherever snails are a major concern. The ecological safety of such a solution must be based on an environmental risk assessment that should include data on the hybridization potential between the introduced species and the native species.

Macrobrachium prawns exhibit a specific reproductive behavior: following ovarian development, females undergo a pre-mating molt (PMM) that signals their reproductive receptivity. Normally, a receptive female is guarded by a fertilizing male (Mallikarjuna Rao 1965). This guarding behavior is crucial for a successful insemination since the PMM renders the female highly vulnerable to cannibalism (Sandifer \& Smith 1985). As mentioned, the reproductive behavior of $M$. rosenbergii has been extensively studied (Chow et al. 1982, Barki et al. 1991), but this is not the case for $M$. vollenhovenii, and clearly, interactions between the 2 species have not been studied to date. Insofar as both species exhibit similar sizes and include large individuals (exceeding 200 g) (Kuris et al. 1987, Savaya Alkalay et al. 2014), they are presumably 2 of the largest of all the Macrobrachium species. 
Although the body shapes of various Macrobrachium species are similar, clear differences are apparent with respect to the last segment of the second chelae (i.e. propodus) in terms of shape, size and texture (Short 2004, Sarkar et al. 2012, Soundarapandian et al. 2014). However, the morphologies and behaviors of only a few Macrobrachium species have been rigorously studied. For example, the claws of $M$. rosenbergii males have been exhaustively detailed and are now used to distinguish between different male morphotypes (Kuris et al. 1987). The blue-claw male morphotype, the largest in the population, is dominant and territorial and exhibits high reproductive success in the context of the social structure of $M$. rosenbergii populations. Because male morphotypes - and hence social structure-in $M$. vollenhovenii have not been described yet, in this study we only included similarly large-sized males of both species with a specific focus on the hybridization potential of $M$. rosenbergii males and $M$. vollenhovenii females. We recorded both cross-species encounters and artificial inseminations (resulting in sperm-egg interactions), to examine the potential for $M$. rosenbergii male and $M$. vollenhovenii female hybridization, from behavioral and physiological perspectives.

\section{MATERIALS AND METHODS}

\section{Animals and morphological comparisons}

All prawns used in this study were kept in freshwater recirculated aquaculture system (RAS) tanks outfitted with biomechanical filters. All-male Macrobrachium rosenbergii prawns were supplied by the Tiran group through Colors (Hatzeva) and were held in 1001 tanks in facilities at Ben-Gurion University of the Negev (BGU), Beer-Sheva, Israel. M. rosenbergii prawns were fed 3 times a week with shrimp pellets (Raanan Fish Feed, I.Z Milout, $40 \%$ protein) and once a week with frozen food (Artemia and bloodworms, Ocean Nutrition). Water temperature ranged between 25 and $29^{\circ} \mathrm{C}$.

M. vollenhovenii prawns for the cross-breeding experiments were collected during 2016 around the Diama dam in the Saint-Louis region of Senegal $\left(16^{\circ} 12^{\prime} 52.65^{\prime \prime} \mathrm{N}, 25^{\circ} 20^{\prime} 16.07^{\prime \prime} \mathrm{W}\right)$ and were held at the hatchery of Espoir Pour La Santé (EPLS) $\left(16^{\circ} 03^{\prime} 05.0^{\prime \prime} \mathrm{N}, 16^{\circ} 25^{\prime} 58.9^{\prime \prime} \mathrm{W}\right)$ in $500 \mathrm{l}$ RAS tanks. M. vollenhovenii prawns were fed 3 times a week with fresh shrimp from the local market. Water temperature ranged between 24 and $29^{\circ} \mathrm{C}$. The sex and weight of each animal were recorded.
To conduct our study, we looked for comparable males of the 2 species in terms of body size and claw morphometry. The morphologies of individuals of both species were compared using a published dataset of 781 single-aged $M$. rosenbergii males from aquaculture ponds in India (Aflalo et al. 2012) compared with our dataset of 475 multi-aged wild $M$. vollenhovenii males that we collected during 2013 and 2016 from the Senegal River. In preparation for the study, $M$. rosenbergii individuals were differentiated according to the 3 morphotypes defined by Kuris et al. (1987), namely small males (SM), orange claw (OC) and blue claw (BC), based on the propodus-tocarapace length ratio. Insofar as $M$. vollenhovenii morphotypes could not be defined from the present study, we focused in this study only on large $M$. vollenhovenii males (>100 g), which are similar in size to $M$. rosenbergii BC males (Aflalo et al. 2012) (Table 1). To explore the differences in the propodus length (PL) to carapace length (CL) ratio among the 4 groups (SM, OC and BC $M$. rosenbergii, and large $M$. vollenhovenii), a 1-way ANOVA test was conducted using Statistica 12 (StatSoft 2013). The assumptions of normality and homogeneity of variances were tested through Shapiro-Wilk and Levene's test, respectively. The assumptions were not met, therefore the data were log-transfomed. The post-hoc test was Tukey HSD and the level of significance used was 0.05 . For the study, comparably sized males with similar PL/CL ratios were selected from both species.

\section{Pre-cross-breeding}

To verify that the $M$. rosenbergii males selected for shipment from Israel to Senegal were indeed reproductively viable, a representative sample of $10 \mathrm{BC}$ males were stocked individually in a RAS, each comprising a $100 \mathrm{ltank}$, and 3 reproductive females were added to each tank. The tanks were monitored daily to identify PMM females and successful fertilizations.

Table 1. Morphological data of Macrobrachium rosenbergii males of 3 morphotypes (SM: small males; OC: orange claw; BC: blue claw) and large $M$. vollenhovenii (Mv) males. PL/CL: propodus length divided by carapace length. Data are mean \pm SE. M. rosenbergii data were acquired from Aflalo et al. (2012)

\begin{tabular}{|llccc|}
\hline & \multicolumn{1}{c}{$\begin{array}{c}\text { SM } \\
(\mathrm{n}=190)\end{array}$} & $\begin{array}{c}\text { OC } \\
(\mathrm{n}=528)\end{array}$ & $\begin{array}{c}\mathrm{BC} \\
(\mathrm{n}=63)\end{array}$ & $\begin{array}{c}\text { Large Mv } \\
(\mathrm{n}=78)\end{array}$ \\
\hline PL/CL & $0.96 \pm 0.01$ & $1.26 \pm 0.01$ & $2.09 \pm 0.03$ & $2.20 \pm 0.3$ \\
Weight (g) & $30.6 \pm 0.8$ & $99.2 \pm 1.4$ & $141.6 \pm 2.2$ & $183.9 \pm 3.8$ \\
\hline
\end{tabular}


Each BC male that successfully fertilized at least 1 female was marked and then isolated in a cage until its shipment to Senegal. Six of the 10 representative $M$. rosenbergii males fertilized $M$. rosenbergii females and were found to be reproductively viable. In total, $50 \mathrm{BC}$ males of the same population were shipped to Senegal and placed in a tank with a receptive $M$. vollenhovenii female for the crossbreeding experiments.

\section{Reproductive behavior of $M$. vollenhovenii}

Aquarium encounters of $M$. vollenhovenii males and females

To compare the reproductive behavior of $M$. vollenhovenii to that of $M$. rosenbergii, which is well known (Chow et al. 1982), we used a Go-Pro Hero 3+ camera to document $35 \mathrm{~h}$ of interaction between a large $M$. vollenhovenii male (>100 g) and spent (mature female that had laid eggs in the past, i.e. reproductively capable) $M$. vollenhovenii females. While $M$. vollenhovenii mating behavior has not been well documented, that of $M$. rosenbergii has been described to include 4 stages, all of which occur after the PMM (Chow et al. 1982):

1. Contact: initial contact is with the antennules, and later, the male grasps the female's pleopods, uropods and pereiopods with his first pereiopods.

2. Seizure of female: the male holds the female between his long second chelipeds.

3. Mounting: the male mounts the female while searching for her sternum with his first pereiopods. The male starts to turn the female upside down in preparation of the actual copulation.

4. Mating: the male completes turning the female over and then angles his first 2 pleopods strongly backwards, after which he presses them firmly on the female's sternum. At this point, he attaches the spermatophore.

In contrast to the study of $M$. rosenbergii mating behavior (Chow et al. 1982), which used females after their PMM, in the current study of M. vollenhovenii mating behavior we used females with developed ovaries (visible through the dorsal carapace) that had not yet undergone PMM. This approach was taken to ensure that we would observe mate selection behavior prior to the female's PMM. The animals were kept in a 1201 aquarium $(100 \times 40$ $\times 40 \mathrm{~cm}$ ) with aeration. During the documentation, the sex ratio was maintained at 4 females to 1 male. Each female was marked on its carapace to facilitate later detection of pre- and post-molt individuals. The aquarium was monitored for male guarding behavior, female PMM and spermatophore attachment.

Cross-species encounters

Six RAS setups, each comprising two 5001 tanks connected to a 2001 biomechanical filter, were used for the cross-species encounter experiments at the EPLS hatchery in the Saint-Louis region of Senegal. This experiment was designed as a pairwise setup. In each RAS system, 1 tank served as the positive control and the other as the treatment group. This was set to eliminate the effects of any differences in the water conditions between the treatments and controls. Each positive control tank was stocked with 1 mature $M$. vollenhovenii male and 3 spent M. vollenhovenii females. Similarly, each treatment tank contained $1 \mathrm{M}$. rosenbergii $\mathrm{BC}$ male and 3 spent $M$. vollenhovenii females. All control and treatment tanks were monitored each morning to record molting events, gonad development, reproductive behavior and fertilization. Water temperature was maintained between 24 and $29^{\circ} \mathrm{C}$. Each female that laid eggs was removed to a different tank where it was housed separately in a marked cage that was monitored daily for embryo development. To maintain the 1:3 sex ratio throughout the experimental period, each removed female that laid eggs was replaced with a new spent female. A total of $23 \mathrm{~h}$ of underwater video (Go-Pro Hero 3+ camera) was recorded and further used to analyze behavioral patterns. To compare the reproductive performance of the treatment and control groups, the following events were quantified: (1) the number of females that performed PMM, (2) the number of females that spawned, (3) the number of cannibalized females, (4) the numbers of viable spawns (i.e. egg hatched and subsequent embryonic development was observed) and (5) the number of egg batches that were disposed.

\section{Artificial insemination}

Artificial insemination must be done within a short time-window of a few hours following the female's PMM, in which the female is reproductively receptive. In addition, the female should be voided of a spermatophore attached to her sternum. To acquire receptive $M$. vollenhovenii females without attached spermatophores, M. vollenhovenii 'detector' males 

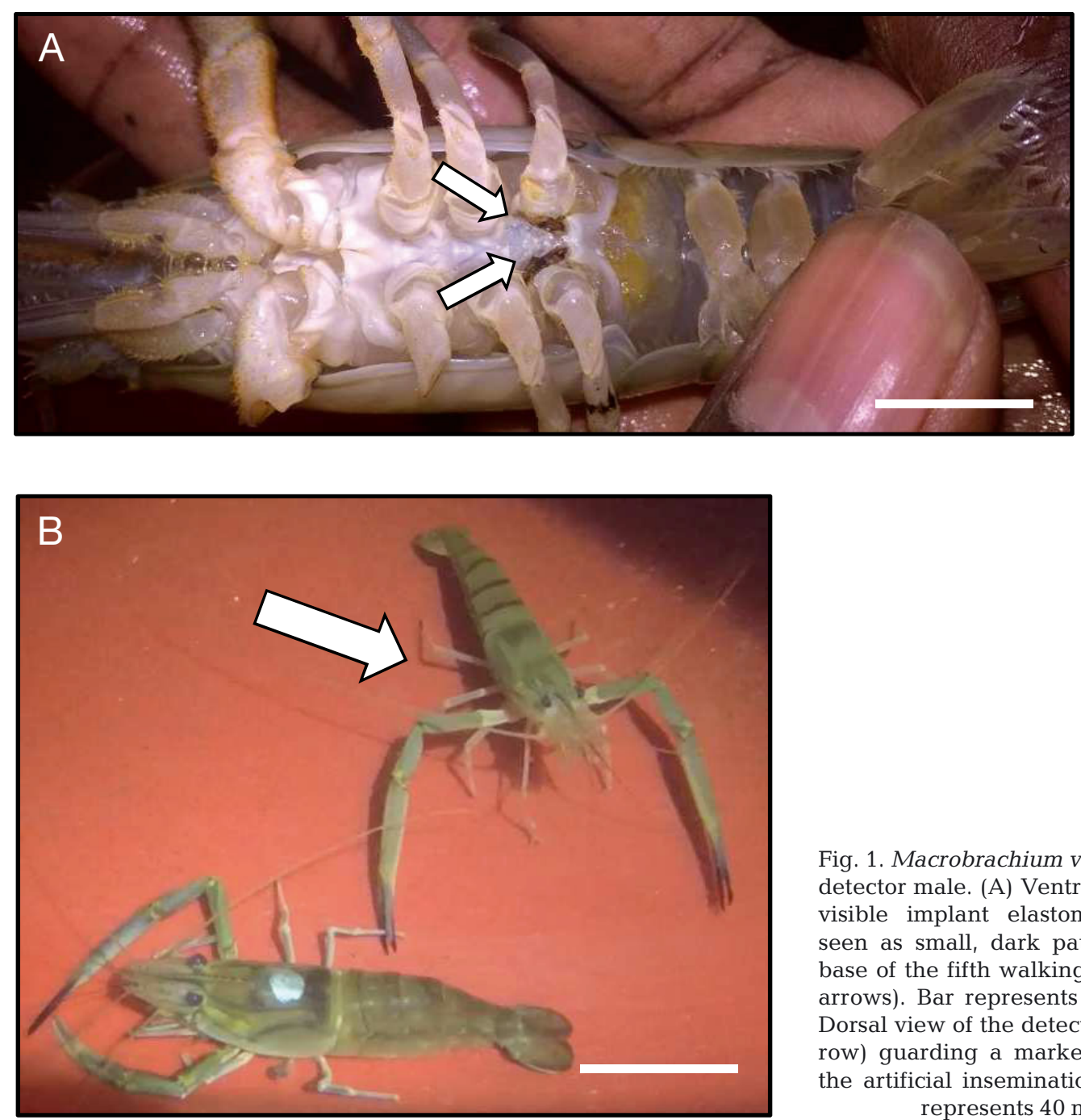

Fig. 1. Macrobrachium vollenhovenii detector male. (A) Ventral view. The visible implant elastomer can be seen as small, dark patches at the base of the fifth walking legs (white arrows). Bar represents $15 \mathrm{~mm}$. (B) Dorsal view of the detector male (arrow) guarding a marked female in the artificial insemination tank. Bar represents $40 \mathrm{~mm}$

that were unable to eject their spermatophores were used (Sandifer \& Smith 1979, 1985, Ra'anan \& Sagi 1985). Detector M. vollenhovenii males were created by effectively sealing their gonophores by injecting a visible implant elastomer (Fig. 1A). To ensure that the sealing was successful, a small drop of 'Super Glue' was applied to the top of each gonopore (Fig. 1A). The resulting detector males exhibited normal reproductive behavior but were unable to eject spermatophores. Two detector males and 12 reproductive (spent) $M$. vollenhovenii females were stocked in each of two $3000 \mathrm{l}$ tanks attached to a $400 \mathrm{l}$ biomechanical filter. All females were marked with a waterproof marker on the dorsal side of their carapaces to facilitate the identification of freshly molted females. Every morning the tanks were monitored for receptive females; the absence of the mark on their dorsal carapace, their soft cuticle and being guarded by the detector male indicated they were ready for artificial insemination (Fig. 1B). Artificial insemination was performed using the method described by Sandifer et al. (1984). In brief, electrodes or an electro ejaculator was placed on the base of the fifth walking legs of a large, mature male where the gonophore is located. To cause the males to eject spermatophores, the animal was stimulated with a voltage of $4-6 \mathrm{~V}$ for 1-2 s, and spermatophores were collected by forceps and deposited on the receptive females' sperm receptacle area (ventral side, between the base of the third and fifth periopods). Each female that was artificially inseminated with spermatophores, whether of $M$. vollenhovenii (control, 8 attempts) or M. rosenbergii (treatment, 12 attempts) origin, was kept in a separate, marked, floating basket to facilitate daily 
monitoring. Females were monitored until eggs were laid. In the event that the eggs were retained on the female's pleopods, embryonic development was periodically monitored under a microscope.

\section{Phylogenetic analyses}

The analysis involved 24 nucleotide sequences of the $16 \mathrm{~S}$ ribosomal RNA gene that were found in the NCBI database and their accession numbers are presented in Supplement 1 at www.int-res.com/articles/ suppl/q010p487_supp/. The crayfish Cherax quadricarinatus serves as an outgroup. Evolutionary analyses were conducted in MEGA6 (Tamura et al. 2013). The evolutionary history was inferred using the neighbor-joining method (Saitou \& Nei 1987).

\section{RESULTS}

\section{Morphological comparisons}

Adult Macrobrachium vollenhovenii males (475) and females (292) were collected. The males averaged $64.2 \pm 2.6 \mathrm{~g}$ (mean $\pm \mathrm{SE})$ with a range of 4 to $235 \mathrm{~g}$ and the females averaged $45.3 \pm 1.4 \mathrm{~g}$ with a range of 6 to $129 \mathrm{~g}$. The large-sized, mature M. vollenhovenii males found in the present study and in the samples we observed in our previous work in the Senegal River Basin (Savaya Alkalay et al. 2014) were comparable to large $M$. rosenbergii BC males in terms of body size and claw morphometry (Table 1) (Kuris et al. 1987, Aflalo et al. 2012). The PL/CL ratios of the 4 groups of males were significantly different (1-way ANOVA: $F_{1,3}=365.42, \mathrm{p}<$ 0.001) except for the $M$. rosenbergii BC male and the large $M$. vollenhovenii male groups (Tukey's HSD, $\mathrm{p}=0.07$ ). The body and second cheliped morphology of a large $M$. vollenhovenii male (196 g) and a large $M$. rosenbergii BC male is depicted in Fig. 2. These males exhibited similar features in terms of body shape and size, cheliped shape and spination, and PL/CL ratio (Fig. 2A,C). However, a close-up on the tip of the propodus revealed that the teeth on the internal part of the chela are much smaller in size in $M$. rosenbergii (Fig. 2D) than in M. vollenhovenii (Fig. 2B). Clear differences were also observed on the exterior side of the chela: whereas the dactylus in $M$. rosenbergii is covered with velvet-like setae (Fig. 2D), the texture of that area in $M$. vollenhovenii is the same as the rest of the chela.

\section{Behavioral comparisons}

\author{
Aquarium encounters
}

Successful M. vollenhovenii copulation between a male and a female of the species was documented (Video S1 at www.int-res.com/articles/suppl/q010 p487_supp/) from the beginning of the male's guarding behavior, which commenced prior to PMM, through the molting event and until copulation. The continuation of the guarding behavior the following day was also recorded. We observed all 4 stages described for $M$. rosenbergii during $M$. vollenhovenii mating behavior. However, because we used females prior to their PMM, the first stage (contact), as well as many brief 'seizure of female' attempts indicating guarding, were already evident $8 \mathrm{~h}$ before PMM and involved different females in the tank. As the time approached to the PMM of the receptive female, that female spent increasingly longer time in proximity to the guarding male, which protected her from the other females by using his large claws in the seizure posture (see Video S2).

As seen in Video S1, once the female started the actual PMM (1:07), the $M$. vollenhovenii male's behavior was similar to that described for $M$. rosenbergii males, including the 'mounting' and 'mating' stages as described above. Due to the angle of the camera, the actual spermatophore attachment cannot be seen in the video; however, the following day we verified visually the spermatophore attachment in a similar location as in $M$. rosenbergii.

\section{Cross-species encounters}

Thirty successful fertilizations of $M$. vollenhovenii females by conspecific males (positive control) were recorded (Table 2). One such representative case is depicted in Fig. 3. In the treatment tanks, in contrast, 8 receptive females laid eggs in the presence of $M$. rosenbergii males, but in all 8 cases, no spermatophore was observed prior to egg laying. These eggs were therefore not fertilized and were aborted after a few days (Table 2). In addition, we observed 2 cases of a PMM $M$. vollenhovenii female in the presence of a $M$. rosenbergii male that did not guard the female, which was eventually cannibalized by the other females in the tank or by the male itself (Table 2). A representative case of cannibalism associated with a PMM is depicted in Fig. 4A, which is a still image from a $1 \mathrm{~h}$ recording showing that the $M$. rosenbergii male does not exhibit its typical repro- 

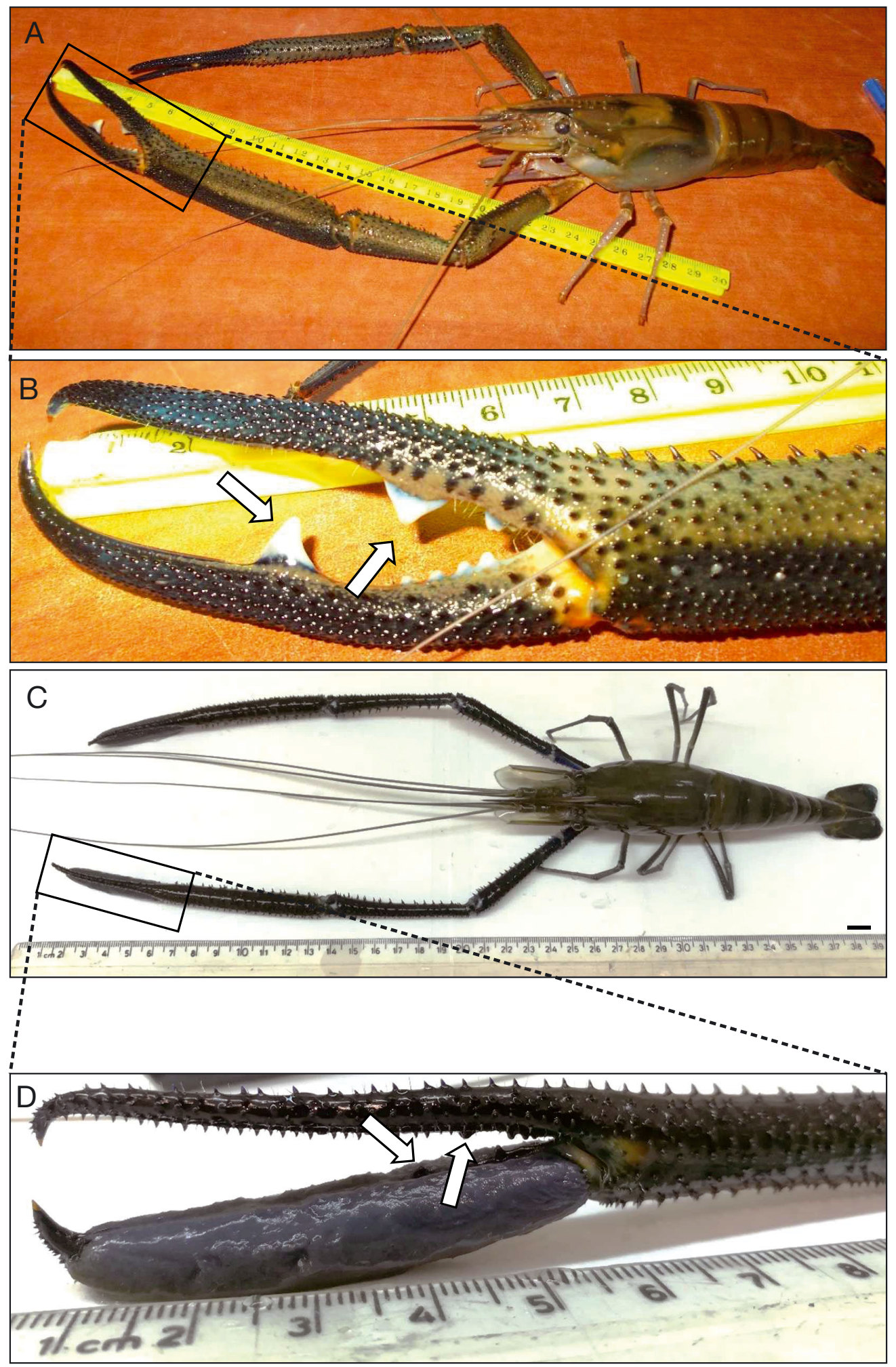

Fig. 2. Dorsal view of large males. (A) Overall view of a Macrobrachium vollenhovenii male. The yellow ruler is $30 \mathrm{~cm}$ long. (B) Enlargement of the tip of the propodus of a M. vollenhovenii male. White arrows indicate the locations of the 2 large propodus teeth. Ruler shows $1 \mathrm{~cm}$ intervals. (C) Overall view of a M. rosenbergii BC male. The ruler is $40 \mathrm{~cm}$ long. Bar represents $1 \mathrm{~cm}$. (D) Enlargement of the tip of the propodus of a $M$. rosenbergii BC male. White arrows indicate the locations of the teeth inside the tip of the propodus 
Table 2. Intra- and cross-species reproductive performance of 3 Macrobrachium vollenhovenii (Mv) females housed with a $M$. vollenhovenii male $(\mathrm{Mv} \times \mathrm{Mv})$ or a Macrobrachium rosenbergii $(\mathrm{Mr})$ male $(\mathrm{Mv} \times \mathrm{Mr})$. PMM: premating molt events; eggs: number of females that laid eggs; dead: death of the female; hatch: number of egg clutches that yielded live larvae; disposed: number of clutches that were aborted

\begin{tabular}{|lccccc|}
\hline & PMM & Eggs & Dead & Hatch & Disposed \\
\hline $\begin{array}{l}\text { Mv } \times \mathrm{Mv} \\
\text { control }\end{array}$ & 30 & 30 & 2 & 27 & 1 \\
$\begin{array}{l}\text { Mv } \times \mathrm{Mr} \\
\text { treatment }\end{array}$ & 10 & 8 & 2 & 0 & 8 \\
\hline
\end{tabular}

ductive behavior (i.e. guarding), while other M. vollenhovenii females continuously irritate the freshly molted, receptive female. In an additional case of cannibalism (Fig. 4B), the M. rosenbergii male itself preyed upon a receptive $M$. vollenhovenii female instead of exhibiting guarding behavior.

\section{Artificial insemination}

Four successful cases of artificial insemination (out of 8 attempts) were recorded in the control group, where $M$. vollenhovenii spermatophores were deposited on receptive $M$. vollenhovenii females. The treatment was deemed successful when the berried females held their broods until embryonic development. In contrast, none of the 12 attempts at artificial insemination in the treatment group, in which $M$. rosenbergii spermatophores were deposited on receptive $M$. vollenhovenii females, was successful (Table 3). These females lost their eggs within 3 to $7 \mathrm{~d}$ post laying. Representative clutches from both the control (Fig. 5A) and treatment (Fig. 5B) groups were photographed under a microscope. Eggs from the control group exhibited normal embryonic development for Day 6 of growth, as evidenced by the clearly visible head and tail of the embryo, while the eggs from the treatment group were devoid of embryos and were aborted.

\section{Phylogenetic analyses}

The optimal tree with the sum of branch length = 1.00970234 is shown in Fig. 6. All positions containing gaps and missing data were eliminated. There was a total of 408 positions in the final dataset. The percentage of replicate trees in which the associated taxa clustered together in the bootstrap test (1000 replicates) are shown next to the branches (Felsenstein 1985). The tree is drawn to scale, with branch lengths in the same units as those of the evolutionary distances used to infer the phylogenetic tree. The evolutionary distances, computed using the maximum composite likelihood method (Tamura et al. 2004), are expressed in units of the number of base substitutions per site.

\section{DISCUSSION}

Accounting for $17 \%$ of the global population, Africa produces only $2 \%$ of global aquaculture biomass, with crustacean culture at a negligible scale (www. fao.org/fishery/). One of the most promising candidates for crustacean aquaculture in Africa is the freshwater prawn Macrobrachium rosenbergii, which is not a native species. Monosex culture ensures that even escapees from aquaculture operations cannot reproduce and become an invasive species (SilvaOliveira et al. 2011); however, the possibility of cross-

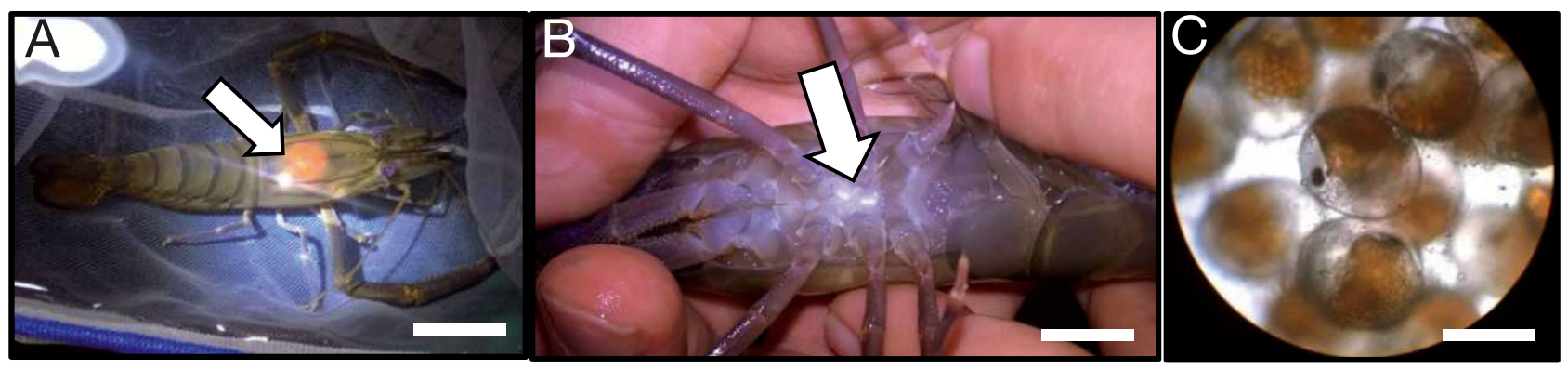

Fig. 3. Outcomes of encounters between Macrobrachium vollenhovenii males and receptive M. vollenhovenii females. (A) Female dorsal view showing a developed ovary (arrow). Bar represents $2 \mathrm{~cm}$. (B) Female ventral view - spermatophores are deposited on the female's receptaculum (arrow). Bar represents $1 \mathrm{~cm}$. (C) Examination of fertilized eggs under a microscope. Eyed eggs indicate normal embryonic development. Bar represents $0.2 \mathrm{~mm}$ 

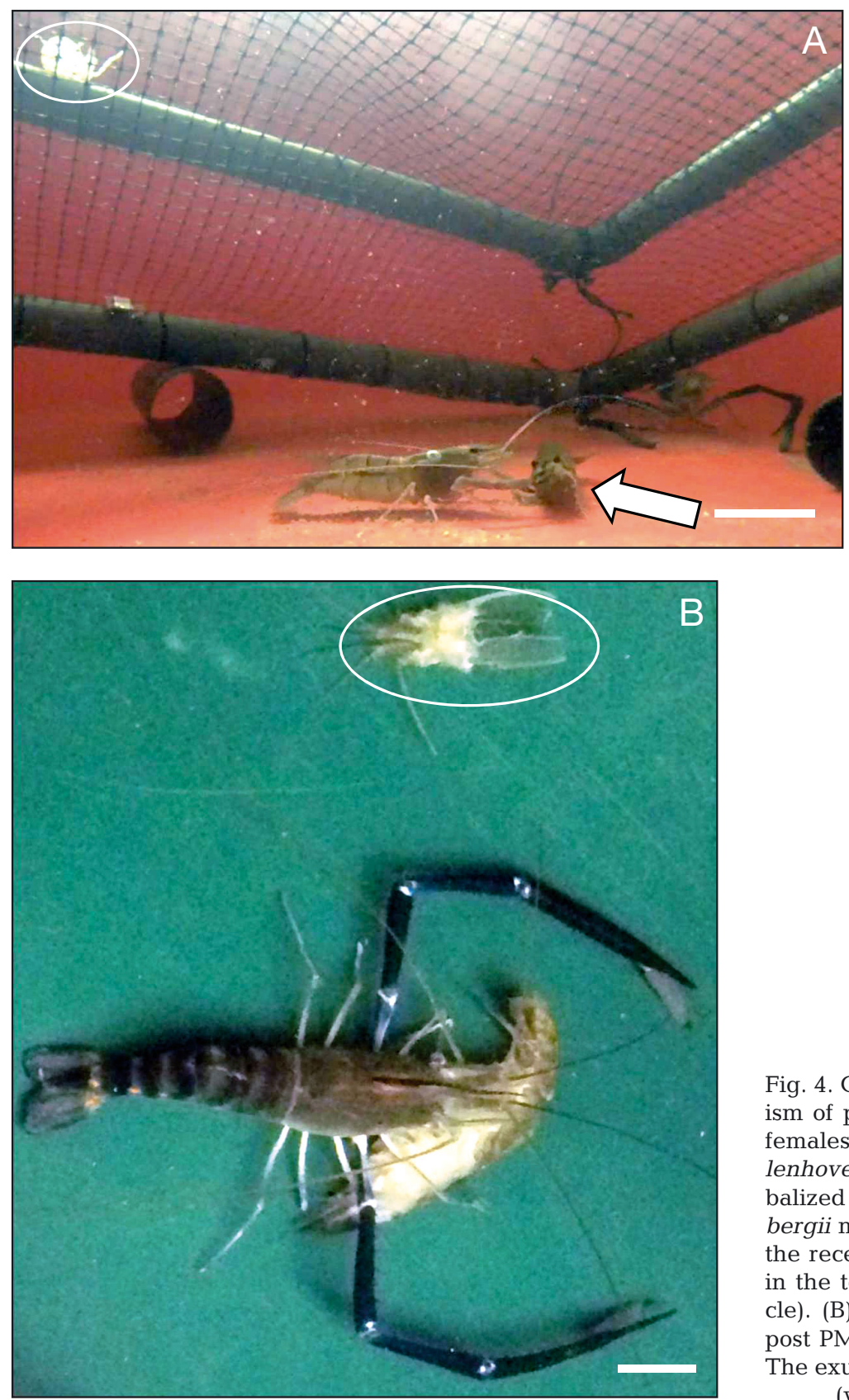

Fig. 4. Cross-species encounters and cannibalism of post pre-mating molt (PMM) receptive females. (A) A receptive Macrobrachium vollenhovenii female (white arrow) being cannibalized by another female, while the $M$. rosenbergii male (seen at the back) is not guarding the receptive female. The exuvia can be seen in the top left corner of the image (white circle). (B) M. rosenbergii male cannibalizing a post PMM receptive $M$. vollenhovenii female. The exuvia can be seen at the top of the image (white circle). Bar represents $4 \mathrm{~cm}$

Table 3. Artificial insemination of Macrobrachium vollenhovenii (Mv) females using $M$. vollenhovenii spermatophores (Mv $\times$ $\mathrm{Mv})$ or $M$. rosenbergii $(\mathrm{Mr})$ spermatophores $(\mathrm{Mv} \times \mathrm{Mr})$. Insemination attempts: number of artificial insemination procedures that were conducted; eggs laid: number of females that laid eggs following the artificial insemination; eggs not laid: number of females that did not lay eggs following the artificial insemination attempt; eggs hatched: number of egg clutches that successfully hatched following the artificial insemination; eggs discarded: number of egg clutches that were laid following the artificial insemination, but were discarded; dead female: number of females that died following the artificial insemination attempt

\begin{tabular}{|lcccccc|}
\hline & Insemination attempts & Eggs laid & Eggs not laid & Eggs hatched & Eggs discarded & Dead female \\
\hline Mv $\times$ Mv control & 8 & 7 & 1 & 4 & 3 & 0 \\
$\mathrm{Mv} \times$ Mr treatment & 12 & 10 & 2 & 0 & 9 & 1 \\
\hline
\end{tabular}



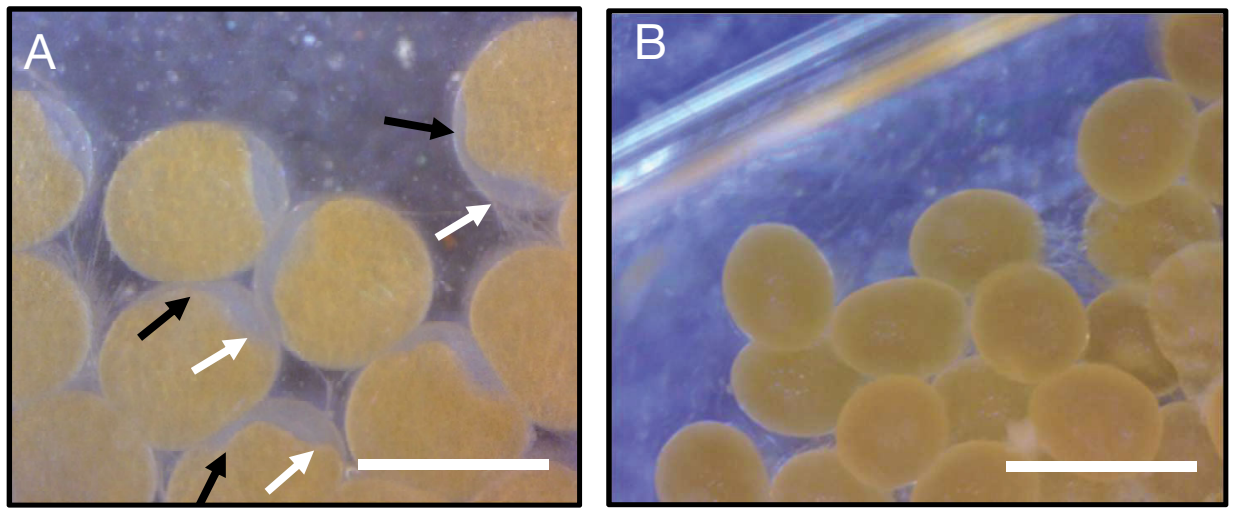

Fig. 5. Egg development following artificial insemination. (A) Positive control: embryonic development 6 d after insemination of Macrobrachium vollenhovenii eggs with conspecific spermatophore. The embryos are visible and their heads and tails are marked with white and black arrows, respectively. Bar represents $0.2 \mathrm{~mm}$. (B) Treatment group: unfertilized M. vollenhovenii eggs, $4 \mathrm{~d}$ after insemination with $M$. rosenbergii spermatophore. No embryo development is apparent. Bar represents $0.2 \mathrm{~mm}$

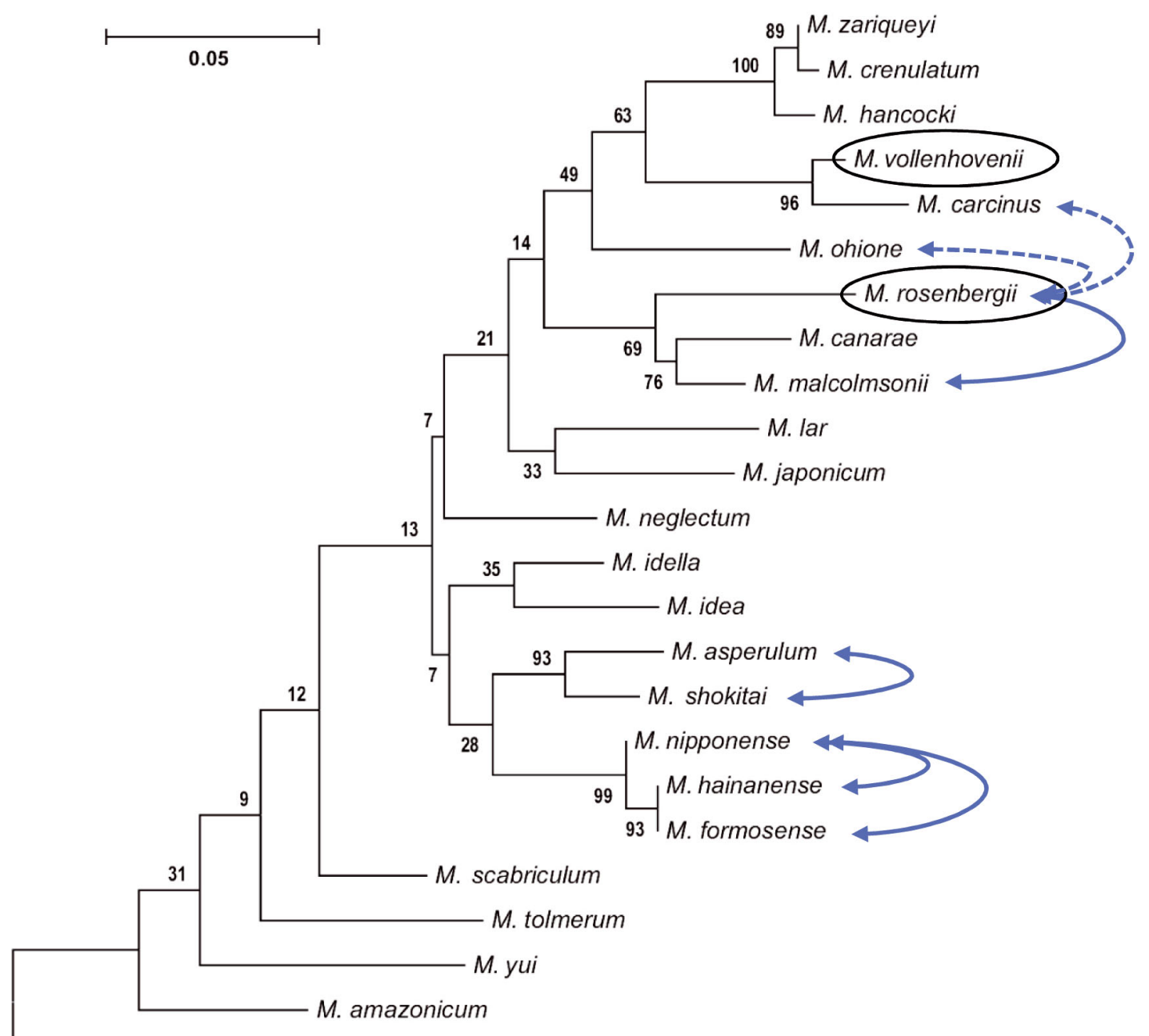

Cherax quadricarinatus

Fig. 6. Evolutionary relationships of 23 Macrobrachium species according to mitochondrial 16S gene. M. rosenbergii and M. vollenhovenii are shown in black circles. Solid and dashed arrows between different species represent successful and unsuccessful cross-species hybridization attempts, respectively 
breeding with local species should also be considered to ensure that $M$. rosenbergii aquaculture is indeed responsible. Our study addressed this question with respect to the African river prawn M. vollenhovenii, and interbreeding between these species was found to be unlikely due to significant reproductive barriers. This opens the path for the introduction of all-male $M$. rosenbergii for aquaculture purposes in Africa.

In addition to their aquaculture potential, all-male M. rosenbergii could be exploited as biocontrol agents against schistosomiasis (Roberts \& Kuris 1990, Sokolow et al. 2014, 2015). The observed feasibility of biological control, together with the limited success of drug treatment, strongly indicate that viable schistosomiasis control may be achieved by adopting a multi-pronged strategy. While drug treatment will reduce disease intensity and prevalence, biocontrol will lower its reinfection rate. To achieve these goals, large quantities of the biocontrol agent will be required, and we suggest exploiting the readily available non-breeding monosex populations of $M$. rosenbergii for this purpose (Savaya-Alkalay \& Sagi 2016, Savaya-Alkalay et al. 2018). Prior to its practical application, however, rigorous environmental assessments, including, but not limited to, ruling out the possibility of interbreeding between $M$. rosenbergii and the local prawn $M$. vollenhovenii, are needed to ensure the safety of this novel approach.

While the mating behavior and claw appearance of M. rosenbergii males are well described (Chow et al. 1982, Kuris et al. 1987), similar information about M. vollenhovenii is lacking. A comparative study performed with $M$. vollenhovenii specimens and adult $M$. rosenbergii animals (Aflalo et al. 2012) found that the large males of the 2 species were similarly sized, which was also reflected in their claw morphometric data as determined by the PL/CL ratio. Other than the relative sizes and teeth occurrence on the claws, the morphologies of the propodus segments of the 2 species differed in terms of texture. The similarities we found in the morphological parameters of the large males of the 2 species led to their selection for the comparative reproductive study. The dearth of information about $M$. vollenhovenii, however, particularly the lack of clear morphotype definitions in the context of the social structure of $M$. vollenhovenii males, dictates the need for further study of this species.

As reported above, we did not find any major differences between pre- and post-PMM mating behaviors of the 2 species. However, when $M$. rosenbergii males and $M$. vollenhovenii females were stocked in the same tank, neither fertilization nor typical repro- ductive guarding behavior occurred, and in some cases, we observed female mortality due to cannibalism. These results and the failure of all attempts at artificial insemination suggest that $M$. rosenbergii males and $M$. vollenhovenii females cannot crossbreed under any conditions and that 2 levels of pre-zygotic barriers (i.e. behavioral and physiological) exist.

Successful breeding between Macrobrachium species has been reported only in those species that are naturally present in the same habitat, that are not geographically isolated from one another and that are closely related phylogenetically. To the best of our knowledge, only 4 hybridization attempts have resulted in viable offspring: $M$. nipponense $\times M$. formosense (Uno \& Fujita 1972), $M$. asperulum $\times M$. shokitai (Shokita 1978), M. nipponense $\times$ M. hainanense (Fu et al. 2004) and M. rosenbergii $\times$ M. malColmsonii (Sankolli et al. 1980, Soundarapandian \& Kannupandi 2000). All 4 of these pairings meet the 3 criteria stated above for successful hybridization (Fig. 6). In contrast, hybridization attempts between geographically isolated or phylogenetically distant species have not succeeded to date (Sandifer et al. 1980, Graziani et al. 2003). M. rosenbergii and $M$. vollenhovenii that originate from geographically isolated areas (South-East Asia and West Africa, respectively) are also phylogenetically remote, as can be seen in the phylogenetic tree (Fig. 6).

In conclusion, we call for responsible field experiments to investigate $M$. rosenbergii all-males for aquaculture and biocontrol in Africa. Our study is the first step towards the introduction of non-native and non-invasive $M$. rosenbergii prawns into West Africa. Additional risk assessment is warranted prior to such introduction, including additional cross-breeding attempts with local Macrobrachium spp. (if present) and a comprehensive environmental survey to be followed by a contained field experiment. Once environmental concerns have been addressed appropriately, commercial aquaculture operations and large-scale biocontrol efforts could be permitted, to the benefit of local communities in West Africa.

Acknowledgements. This study was supported in part by grants from Grand Challenges Canada through EPLS (5146) and the Bill and Melinda Gates Foundation through Stanford University (7047). We thank Roy Alford and Jonathan Molcho for animal maintenance at BGU. For the supply and shipment of $M$. rosenbergii prawns from Israel to Senegal, we thank Tiran Shipping Group Ltd. through their subcontractor, Mr. Ran Epshtein, Colors Ltd. We thank Mrs. Salimata Fall and Mr. Moussa Sene for animal maintenance in Senegal. 


\section{LITERATURE CITED}

Aflalo ED, Raju DVSN, Bommi NA, Verghese JT and others (2012) Toward a sustainable production of genetically improved all-male prawn (Macrobrachium rosenbergii): evaluation of production traits and obtaining neo-females in three Indian strains. Aquaculture 338-341:197-207

Barki A, Karplus I, Goren M (1991) The agonistic behavior of the three male morphotypes of the freshwater prawn Macrobrachium rosenbergii (Crustacea, Palaemonidae). Behaviour 116:252-277

Bauer RT (2011) Amphidromy and migrations of freshwater shrimps. ii. Delivery of hatching larvae to the sea, return juvenile upstream migration, and human impacts. In: Asakura A (ed) New frontiers in crustacean biology. Koninklijke Brill NV, Leiden

Chow S, Ogasawara Y, Taki Y (1982) Male reproductive system and fertilization of the palaemonid shrimp Macrobrachium rosenbergii. Bull Jpn Soc Sci Fish 48:177-183

Cowie RH, Hayes KA (2012) Apple snails. In: Francis RA (ed) A handbook of global freshwater invasive species. Earthscan, Milton, p 207-221

Felsenstein J (1985) Confidence limits on phylogenies: an approach using the bootstrap. Evolution 39:783-791

Fu H, Gong Y, Wu Y, Xu P, Wu C (2004) Artificial interspecific hybridization between Macrobrachium species. Aquaculture 232:215-223

* Graziani C, Moreno C, Villarroel E, Orta T, Lodeiros C, De Donato M (2003) Hybridization between the freshwater prawns Macrobrachium rosenbergii (De Man) and $M$. carcinus (L.). Aquaculture 217:81-91

Kuris AM, Raanan Z, Sagi A, Cohen D (1987) Morphotypic differentiation of male Malaysian giant prawns, Macrobrachium rosenbergii. J Crustac Biol 7:219-237

Makombu JG, Oben PM, Oben BO, Gaudin GL and others (2014) Complete larval development of the fresh water prawn Macrobrachium vollenhovenii in Cameroon. J Appl Aquacult 26:310-328

Mallikarjuna Rao R (1965) Breeding behaviour in Macrobrachium rosenbergii (de Man). Fish Technol 2:19-25

Marioghae IE (1988) M. vollenhovenii: guidelines for the implementation of the proposed pilot culture programme, making use of available infrastructure. Lagos State Agriculture Development Authority, Agege

Marioghae IE, Ayilna OA (1995) The reproductive biology and culture of Macrobrachium vollenhovenii and Macrobrachium macrobrachion in Nigeria. Nigerian Institute for Oceanography and Marine Research, Port Harcourt

Mitchell AJ, Hobbs MS, Brandt TM (2007) The effect of chemical treatments on red-rim melania Melanoides tuberculata, an exotic aquatic snail that serves as a vector of trematodes to fish and other species in the USA. N Am J Fish Manage 27:1287-1293

Ra'anan Z, Sagi A (1985) Alternative mating strategies in male morphotypes of the freshwater prawn Macrobrachium rosenbergii (de Man). Biol Bull 169:592-601

Roberts JK, Kuris AM (1990) Predation and control of laboratory populations of the snail Biomphalaria glabrata by the freshwater prawn Macrobrachium rosenbergii. Ann Trop Med Parasitol 84:401-412

Saitou N, Nei M (1987) The neighbor-joining method: a new method for reconstructing phylogenetic trees. Mol Biol Evol 4:406-425

Sandifer PA, Smith TI (1979) A method for artificial insemination of Macrobrachium prawns and its potential use in inheritance and hybridization studies. Proc World Mariculture Soc 10:403-418

Sandifer PA, Smith TI (1985) Freshwater prawns. In: Huner JV, Brown EE (eds) Crustacean and mollusc aquaculture in the United States. Avi Publishing, Westport, CT, p 66-126

Sandifer PA, Lynn JW (1980) Artificial insemination of caridean shrimp. In: Clark WH Jr, Adams TS (eds) Advances in invertebrate reproduction. Elsevier, Amsterdam, p 271-288

Sandifer PA, Lawrence AL, Harris SG, Chamberlain GW, Stokes AD, Bray WA (1984) Electrical stimulation of spermatophore expulsion in marine shrimp, Penaeus spp. Aquaculture 41:181-187

Sankolli K, Shenoy S, Jalihal D, Almelkar G (1980) Crossbreeding experiment with the giant freshwater prawn Macrobrachium rosenbergii and Macrobrachium malcomsonii. In: New MB (ed) Giant prawn farming. Elsevier, Amsterdam, p 91-98

Sarkar I, Basu A, Dutta S, Roy S (2012) Male mating tactics and mating activity in freshwater prawn, Macrobrachium dayanum (Henderson, 1893) Paleomonidae: Caridae. Int J Aquat Sci 3:56-70

Savaya-Alkalay A, Sagi A (2016) Biotechnology, biocontrol and conservation: potential approaches-harnessing RNAi-based sex-differentiation manipulations in decapods. In: Kawai T, Cumberlidge N (eds) A global overview of the conservation of freshwater decapod crustaceans. Springer, Cham, p 323-338

Savaya Alkalay A, Rosen O, Sokolow SH, Faye YP and others (2014) The prawn Macrobrachium vollenhovenii in the Senegal River basin: towards sustainable restocking of all-male populations for biological control of schistosomiasis. PLOS Negl Trop Dis 8:e3060

Kavaya-Alkalay A, Ovadia O, Barki A, Sagi A (2018) Sizeselective predation by all-male prawns: implications for sustainable biocontrol of snail invasions. Biol Invasions 20:137-149

Shokita S (1978) Larval development of interspecific hybrid between Macrobrachium asperulum from Taiwan and Macrobrachium shokitai from the Ryukyus [Japan]. Bull Jpn Soc Sci Fish 44:1187-1195

Short J (2004) A revision of Australian river prawns, Macrobrachium (Crustacea: Decapoda: Palaemonidae). Hydrobiologia 525:1-100

Kilva-Oliveira GC, Ready JS, Iketani G, Bastos S, Gomes G, Sampaio I, Maciel C (2011) The invasive status of Macrobrachium rosenbergii (De Man, 1879) in Northern Brazil, with an estimation of areas at risk globally. Aquat Invasions 6:319-328

StatSoft (2013) Statistica 12. Stat Soft, Tulsa, OK

* Sokolow SH, Lafferty KD, Kuris AM (2014) Regulation of laboratory populations of snails (Biomphalaria and Bulinus spp.) by river prawns, Macrobrachium spp. (Decapoda, Palaemonidae): implications for control of schistosomiasis. Acta Trop 132:64-74

Sokolow SH, Huttinger E, Jouanard N, Hsieh MH and others (2015) Reduced transmission of human schistosomiasis after restoration of a native river prawn that preys on the snail intermediate host. Proc Natl Acad Sci USA 112: 9650-9655

Sokolow SH, Wood CL, Jones IJ, Swartz SJ and others (2016) Global assessment of schistosomiasis control over the past century shows targeting the snail intermediate host works best. PLOS Negl Trop Dis 10:e0004794

Sokolow SH, Jones IJ, Jocque M, La D and others (2017) 
Nearly 400 million people are at higher risk of schistosomiasis because dams block the migration of snail-eating river prawns. Philos Trans R Soc B 372:20160127

Soundarapandian P, Kannupandi T (2000) Larval production by crossbreeding and artificial insemination of freshwater prawns. Indian J Fish 47:97-101

Soundarapandian P, Sudhakar S, Varadharajan D, Dinakaran G (2014) Mating behaviour in different size males of Macrobrachium idae (Heller, 1862). J Cytol Histol 5:1

Southgate VR (1997) Schistosomiasis in the Senegal River Basin: before and after the construction of the dams at Diama, Senegal and Manantali, Mali and future prospects. J Helminthol 71:125-132

Swartz SJ, De Leo GA, Wood CL, Sokolow SH (2015) Infection with schistosome parasites in snails leads to increased predation by prawns: implications for human schistosomiasis control. J Exp Biol 218:3962-3967

Tamura K, Nei M, Kumar S (2004) Prospects for inferring very large phylogenies by using the neighbor-joining method. Proc Natl Acad Sci USA 101:11030-11035

Editorial responsibility: Ian Fleming, St. John's, Newfoundland and Labrador, Canada
Tamura K, Stecher G, Peterson D, Filipski A, Kumar S (2013) MEGA6: Molecular Evolutionary Genetics Analysis Version 6.0. Mol Biol Evol 30:2725-2729

Uno Y, Fujita M (1972) Studies on the experimental hybridization of freshwater shrimp Macrobrachium nipponense and $M$. formosense. In: Abstracts of the Second International Ocean Development Conference, 5-7 October 1972, Tokyo, Abstract no. 1762. International Ocean Development Conference and Exhibition, Japan Mangement Association, Tokyo

*Ventura T, Manor R, Aflalo ED, Weil S, Rosen O, Sagi A (2012) Timing sexual differentiation: full functional sex reversal achieved through silencing of a single insulinlike gene in the prawn, Macrobrachium rosenbergii. Biol Reprod 86:90

*Willfuhr-Nast J, Rosenthal H, Udo PJ, Nast F (1993) Laboratory cultivation and experimental studies of salinity effects on larval development in the African River prawn Macrobrachium vollenhovenii (Decapoda, Palaemonidae). Aquat Living Resour 6:115-137

Submitted: April 16, 2018; Accepted: September 10, 2018

Proofs received from author(s): November 6, 2018 